\title{
Soil moisture influence in the soil tillage operations
}

\author{
Petru Cardei ${ }^{1,{ }^{*},}$ Raluca Sfiru ${ }^{1}$, Sebastian Muraru ${ }^{1}$, Paula Condruz ${ }^{1}$ \\ ${ }^{I}$ INMA Bucharest, Informatics and engineering, No 6 Bd Ion Ionescu de la Brad Bucharest, Romania
}

\begin{abstract}
This article presents results obtained by the author in an attempt to introduce new parameters that influence the working process of agricultural soil working machines, in the classical formulas that mathematically model the tillage draft force. This article naturally introduces soil moisture. To introduce soil moisture into the calculation formulas of the tillage draft force, other physical parameters affected by soil moisture were used: density, cohesion, adhesion, etc. In this article, is explicitly describes, only the variation of soil density with its moisture. Considering some phenomena such as soil swelling or shrinkage, required the development of an adequate mathematical model of the expression of the density of soil-water mixture, concerning the concentration of water and the densities of dry soil and water. The final formulas obtained are tested to experimental results from the literature. Finally, the author sets out his opinion regarding the use of the results in design calculations and regarding the elevation to the rank of physical law of a mathematical model represented by a formula with a large number of parameters, which in turn are still dependent on many others parameters.
\end{abstract}

\section{Introduction}

The process of soil processing of agricultural land surfaces is fundamental in agriculture. This process has been studied and modelled in many variants. All these variants have certain converging ideas, such as the dependence of the draft force on the second power of the working speed, the depth and the working width, as well as on other parameters which, in one form or another, appear in different models. In [1] I tried to sketch a lot of the parameters that influence the process of interaction between the working organs of the tillage machines and the soil. The summary of the influential parameters is incomplete, especially since some of the parameters are not mechanical, being pedological (texture, structure, compaction and soil composition, for example, organic matter content). The mechanical parameters of the soil depend implicitly on the soil moisture and its pedological parameters. Specifically, mechanical parameters are functions of humidity, but not only of this.

Generally, the model parameters of the main mathematical models of the draft forces generated by the soil tillage machines are themselves functions, which depend on the parameters that characterize the soil. The parameters that characterize the soil are many; in

* Corresponding author: author@email.org 
addition, not all fully quantified (texture). Without simplifying, we would have as model parameters, functions of 20-30 variables (maybe, not all independent). Such entities are very difficult to study, but especially to be known, as an expression, as a form. To determine an approximate dependence, many hypotheses, many calculations, but also many expensive and complex experiences are needed. On the other hand, many of the parameters characteristic of the soil are not, generally, independent. Pedological research has shown some dependencies between these parameters and between these and other groups of parameters: meteorological (as can be considered humidity), agricultural technology used culture, etc. Therefore soil moisture is a very important parameter, which does not appear explicitly in the most popular models of draft force, [12], [11], [29], and [32]. On the other hand, the literature dedicated to soil cultivation abounds with observations on optimal humidity, or optimum humidity ranges for soil tillage, [2], [3], [35-38], and so on. These were reasons for the approach presented in this article, see [39]. The list of names, notations and units of measurement and of the parameters used in this article is given in table 1.

Table 1. The list of names, notations and units of the parameters used.

\begin{tabular}{|l|c|c|}
\hline \multicolumn{1}{|c|}{ Name } & Notation & Unit \\
\hline The volumetric content of water & $\theta$ & - \\
\hline Volume of water & $V_{w}$ & $\mathrm{~m}^{3}$ \\
\hline The total volume of wet material & $V_{w e t}$ & $\mathrm{~m}^{3}$ \\
\hline Volume of soil and vegetation particles & $V_{s}$ & $\mathrm{~m}^{3}$ \\
\hline The volume of air & $V_{a}$ & $\mathrm{~m}^{3}$ \\
\hline Volume of dry soil in the oven & $V_{d r y}$ & $\mathrm{~m}^{3}$ \\
\hline Gravimetric water content & $u, c_{w}$ & - \\
\hline Water mass & $m_{w}$ & $\mathrm{~kg}$ \\
\hline Total mass of wet material & $m_{w e t}$ & $\mathrm{~kg}$ \\
\hline Mass of dry sample & $m_{d r y}$ & $\mathrm{~kg}$ \\
\hline Gravimetric water content & $u^{\prime}$ & - \\
\hline Gravimetric moisture content & $u^{\prime \prime}$ & - \\
\hline Specific density of a material & $d$ & - \\
\hline Specific density of wet material (sample) & $d_{w e t}$ & - \\
\hline The density of any material & $\rho$ & $\mathrm{kg} / \mathrm{m}^{3}$ \\
\hline Water density & $\rho_{w}$ & $\mathrm{~kg} / \mathrm{m}^{3}$ \\
\hline Expansion-shrinkage coefficient of soil due to humidity & $\delta$ & - \\
\hline $\begin{array}{l}\text { Model parameter for the coefficient of expansion and contraction } \\
\text { of the soil }\end{array}$ & $\delta_{0}$ & - \\
\hline Mass concentration of dry soil in moist soil & $c_{d r y}$ & - \\
\hline Mass concentration of water in moist soil & $c_{w}$ & - \\
\hline Draft force & $F$ & $\mathrm{~N}$ \\
\hline Soil cohesion & $c$ & $\mathrm{~Pa}$ \\
\hline Soil-working body adhesion & $c_{a}$ & $\mathrm{~Pa}$ \\
\hline Horizontal blade angle (rake angle) & $\alpha$ & $\mathrm{rad}$ \\
\hline Model parameters & $G, z, t, u_{0}, B$ & - \\
\hline Coefficient analogous to the friction coefficient & $f$ & - \\
\hline Plough weight & $G$ & $\mathrm{~N}$ \\
\hline Coefficient that characterizes specific soil deformation resistance & $b$ & $\mathrm{~Pa}$ \\
\hline Working body width & $a$ & $\mathrm{~m}$ \\
\hline Working depth & $\varepsilon$ & $\mathrm{m}$ \\
\hline $\begin{array}{l}\text { Coefficient which depends on the shape of the active surface of } \\
\text { the body and the soil properties }\end{array}$ & $\varepsilon^{\prime}$ & - \\
\hline Dimensionless coefficient & & \\
\hline & $b$ & \\
\hline
\end{tabular}




\section{Soil moisture - a profoundly involved parameter in the process of interaction between the working organs of the machines for soil tillage and the soil}

According to [5], the moisture or the water content of the soil is the amount of water that is physically bound to the earth, when harvesting and evaporating at $105^{\circ} \mathrm{C}$.

There are many defined parameters to quantify the water concentration in the soil. Thus, for example, according to [4], the volumetric water content is defined by the formula (1):

where:

$$
\theta=\frac{V_{w}}{V_{\text {wet }}}
$$

$$
V_{w e t}=V_{s}+V_{w}+V_{a}
$$

The gravimetric content of water, after [6], is given by the formula:

$$
u=\frac{m_{w}}{m}
$$

For materials that exhibit volume changes when they contain water, such as coal, the gravimetric water content has the modified formula:

$$
u^{\prime}=\frac{m_{w}}{m_{w e t}}
$$

In the field of wood processing, geotechnical and soil science, according to [4], the gravimetric humidity formula is used:

$$
u^{\prime \prime}=\frac{m_{w}}{m_{d r y}}
$$

If the actual specific density of a material is introduced by the formula:

Is obtaining the relation (7):

$$
d=\frac{\rho}{\rho_{w}}
$$

$$
\theta=u \cdot d_{\text {wet }}
$$

The gravimetric water content is calculated taking into account the formula:

$$
m_{w}=m_{w e t}-m_{d r y} \text {. }
$$

Table 2. The optimum moisture range for ploughing, by soil types, after [2].

\begin{tabular}{|c|c|}
\hline Type of the soil & Optimal moisture for ploughing, \% \\
\hline Sandy & $8.0-30.0$ \\
\hline Sandy - clay & $10.0-28.0$ \\
\hline Clay-sandy & $13.0-26.0$ \\
\hline Clay & $15.0-25.0$ \\
\hline Clay-loamy & $17.0-23.0$ \\
\hline Loamy & $18.0-20.0$ \\
\hline
\end{tabular}

In [2] it is shown that performing the ploughing work outside the optimum humidity range leads to an increase of $30-50 \%$ of the ploughing resistance, see also [39]. The same author, in [3], shows that in the case of heavy, clay soils, the optimum humidity range for the soil works is $19-21 \%$, and for light, sandy soils, between 7 and $21 \%$, even up to $28 \%$. In [3], is interesting the following indication of optimality: the optimum moisture at the plough is achieved when the specific resistance at the plough is between $35000 \mathrm{~Pa}$ and $45000 \mathrm{~Pa}$ for light soils and $61000-75000 \mathrm{~Pa}$ for heavy soils. This minimum resistance increases by $10 \%$ on easyily compacted soils and by $30 \%$ on compacted soils.

The emergence of an optimum point in the soil cultivation process is the result of considering an optimization problem with several objective functions, as we have already 
shown: the tensile strength (must be minimized), the quality of the soil processing (must be brought to a value as high as possible, closer to the value quantified by specialists), tractor wheels slip (it must be minimized), the working capacity (it must be maximized), the energy consumption (it must be minimized), the soil compaction (it must be minimized), the wear of the cars (it must be minimized), etc. To take into account several objectives, a multi-objective functional is built, whose minimization guarantees the achievement of a compromise point in the space of the optimization parameters, taking into account the possible restrictions imposed, [25-28].

The optimization of the working regime of the soil tillage machines, having as an objective function only the draft soil tillage force, so far, is not confirmed experimentally. There are works that show that certain factors involved in the mathematical modelling of the working process, present extreme values in usual humidity intervals, [7-8].

One way to obtain the behaviour of some mechanical parameters of the soil in relation to humidity, as described above ([7-8]), is to introduce a phenomenon of variation of the volume of the soil through the absorption or loss of water. According to [9-10] or [34], the property of soils to increase their volume by soaking with water has been called swelling, and the contraction of the soil is the property of the soil to decrease its volume by losing water (drying), an inverse phenomenon of the swelling phenomenon.

The volume variation of the soil is introduced through the variation of the density of the wet soil. The next densities are defined:

$$
\rho_{d r y}=\frac{m_{d r y}}{V_{d r y}}, \rho_{w}=\frac{m_{w}}{V_{w}} .
$$

For the calculation of wet soil density, is proposed the following formula:

$$
\rho_{w e t}=\frac{m_{w e t}}{V_{w e t}}=\frac{m_{d r y}+m_{w}}{\delta \cdot V_{d r y}+V_{w}} \text {. }
$$

In many technical fields, the density calculation of a mixture is calculated with formulas similar to formula (10), considering $\delta=1$. In the hypothesis introduced in this article, if $\delta<1$, then volume contraction occurs, and if $\delta>1$, then the volume expansion of the soil occurs. The mass concentrations of soil and water from the wet soil are defined by the reports:

$$
c_{d r y}=\frac{m_{d r y}}{m_{w e t}}, c_{w}=\frac{m_{w}}{m_{w e t}} .
$$

Using (11) and amplifying the last fraction of (10) with $m_{w e t}{ }^{-1}$, we obtain the expression of the wet soil density depending on the densities of the dry soil, and of the water, the mass content of water and the coefficient of expansion and contraction of the volume of soil at humidification:

$$
\rho_{w e t}=\frac{\rho_{d r y} \rho_{w}}{\delta \cdot\left(1-c_{w}\right) \rho_{w}+c_{w} \rho_{d r y}}
$$

It is noted that the mixture containing only water $\left(c_{w}=1\right)$, has the density of water. For the mixture that is reduced to dry soil $\left(c_{w}=0\right)$, to have the density of the dry soil, the dilationcontraction coefficient is required to have the property: $\delta(0)=1$.

As a result, the coefficient of expansion - volume shrinkage of the soil upon humidification must be a function of humidity, in this case: $\delta=\delta\left(c_{w}\right)$. The coefficient of expansionshrinkage of the soil when humidifying, also depends on other parameters, such as soil texture, its composition and structure. For some graphical representations that try to give a more understandable image of the model (12) for calculating the density of the wet soil, a coefficient of expansion-contraction coefficient of form is considered:

$$
\delta\left(c_{w}\right)=1+c_{w} \cdot \frac{\delta_{0}-1}{u_{s}\left(u_{s}-2 u_{v f}\right)} \cdot\left(c_{w}-2 u_{v f}\right)
$$




\section{Ways to introduce soil moisture in the formulas of the draft force of the soil tillage machines}

For the mathematical models of the tensile strength in which the soil density explicitly appears, it is easy to introduce moisture by replacing the density in the formula with the form (12) of the density, taking into account also (13). An example is a formula proposed in [11]:

$$
F=x \rho b^{2} v^{2}\left(\frac{c+c_{a}}{\rho v^{2}}\right)^{y}\left(\frac{a}{b}\right)^{z}(\sin \alpha)^{t} .
$$

where $x, y, z, t$ are model parameters (they are established for the experimental data corresponding to a particular soil type). An elementary variant containing moisture for formula (14) would be:

$$
\begin{aligned}
F=x b^{2} v^{2-2 y}\left(c\left(c_{w}\right)+c_{a}\left(c_{w}\right)\right)^{y}\left(\frac{a}{b}\right)^{z}(\sin \alpha)^{t} & \left(\frac{\rho_{d r y} \rho_{w}}{1+c_{w} \cdot \frac{\delta_{0}-1}{u_{s}\left(u_{s}-2 u_{v f}\right)} \cdot\left(c_{w}-2 u_{v f}\right) \cdot\left(1-c_{w}\right) \rho_{w}+c_{w} \rho_{d r y}}\right)^{1-y}
\end{aligned}
$$

In the expression (15) of the draft soil tillage force, the parameters $x, y, z, t$ (which can be deduced by the method of the smallest squares, for example, using an experimental data set) may also depend on the soil moisture, texture, structure and composition of the soil. In the same way, due to the density of the wet soil, soil moisture dependence can also be introduced in Goriacikin's formula. Taking into account the statements in [12], Goriacikin's mathematical model for tensile strength can be written as:

where also after [12],

$$
F=f G+k a b+\varepsilon a b v^{2} .
$$

From (16) and (17) is obtained:

$$
\varepsilon=\varepsilon^{\prime} \rho
$$

$$
F=f G+k a b+\varepsilon^{\prime} \rho a b v^{2} .
$$

Considering that in (18), the density is that of the wet soil, given by (12):

$$
\rho=\rho_{\text {wet }} \text {. }
$$

the equation that models the tensile strength after Goriacikin becomes:

$$
F=f\left(c_{w}\right) G+k\left(c_{w}\right) a b+\varepsilon^{\prime} \frac{\rho_{d r y} \rho_{w}}{1+c_{w} \cdot \frac{\delta_{0}-1}{u_{s}\left(u_{s}-2 u_{v f}\right)} \cdot\left(c_{w}-2 u_{v f}\right) \cdot\left(1-c_{w}\right) \rho_{w}+c_{w} \rho_{d r y}} a b v^{2} .
$$

About the parameters $f$ and $k$, it can be assumed that they also depend on the texture of the soil, and $k$ is also variable with the working depth, $a$. After (20), the tensile strength is a function with 10 - 13 arguments, becoming more complicated than the original version, (16). The density of the soil, as well as the tension at vertical penetration, decrease with the organic matter content of the soil, [17] which should be taken into account in a possible extension of the models presented in this article.

\section{Results}

The primary results are mathematical formulas or models (12), (13), (15) and (20).

For soils with variable volume depending on humidity, the variation of the density and the coefficient of expansion-contraction with a mass content of water are given in fig. 1-2. For the value of parameter $\delta_{0}$ smaller than 1 , the variation of soil density is of convex type, and that of the expansion-contraction coefficient is of concave type. If the parameter $\delta_{0}$ takes values greater than 1 , the situation is reversed. This model of variation of soil density with moisture therefore allows convex or concave variations. 


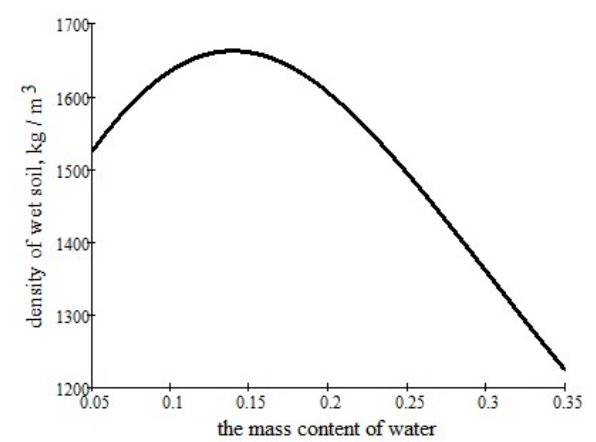

Fig. 1 The dependence of wet soil density on the mass content of water.

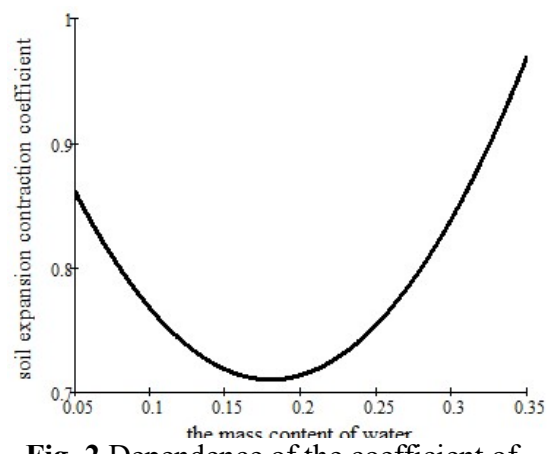

Fig. 2 Dependence of the coefficient of expansion-contraction on the water content.

$\rho_{d r y}=1350 \mathrm{~kg} / \mathrm{m}^{3}$, water density, $\rho_{w}=1000 \mathrm{~kg} / \mathrm{m}^{3}, \delta_{0}=0.85, u_{s}=0.055, u_{v f}=0.18$

The model of the tensile strength (15) is considered, having as its origin the model proposed by [11]. We used the model proposed in [11] with the parameters $x, y, z, t$ determined in the precision and order tests from [14], for the experimental data from [13]. These values may theoretically depend on soil moisture. Because we did not study their dependence on humidity, we take the average values characteristic for the humidity interval in which we worked, $x=0.99882, y=0.88324, z=0.448778, t=0.001703$. Also, for the cohesion and adhesion of the soil to the surfaces of contact with the soil, the average values in the range of humidity in which it was worked are considered: $c=41000 \mathrm{~Pa}, c_{a}=$ $32500 \mathrm{~Pa}$. The angle of the working body with the horizontal is kept constant, $\alpha=30^{\circ}$. In these conditions, the dependence of the draft force, (15), with the soil moisture, for three values of working depth, is given in the fig. 5. The dependence of the same model of the draft force with the working speed is given graphically, in the fig. 6 .

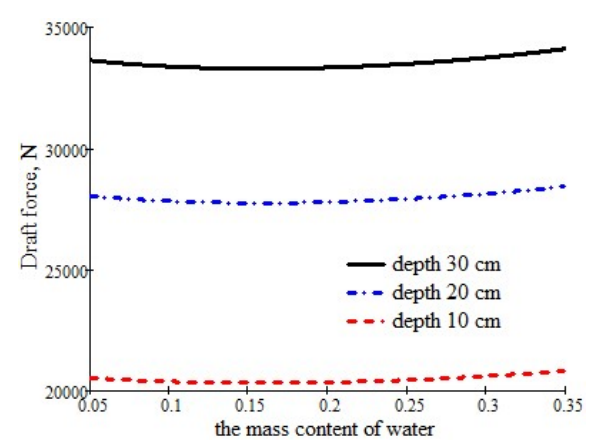

Fig. 3 Variation of the draft force with the soil moisture (three working depth).

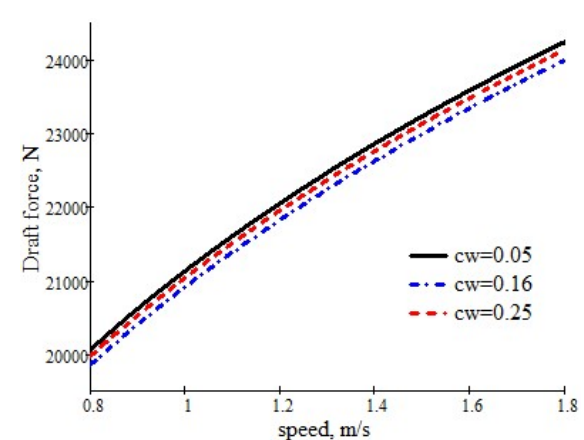

Fig. 4 Dependence of the draft force on the working speed, for three soil moisture.

$$
\rho_{\text {dry }}=1350 \mathrm{~kg} / \mathrm{m}^{3} \text {, water density, } \rho_{w}=1000 \mathrm{~kg} / \mathrm{m}^{3}, \delta_{0}=1.15, u_{s}=0.055, u_{v f}=0.18
$$

It can be observed that the tensile strength (15) has, during the used humidity range, a convex variation, which allows the optimum working humidity to be highlighted, if only the tensile strength is considered as an objective function (fig. 3). The optimum humidity is in the vicinity of the horizontal coordinate of the top of the parabola (13), which models the variation of the density of the wet soil to the mass content of water. The model (15) shows the increase of the tensile strength with the working speed, highlighting the existence of an optimal humidity relative to the objective function of the draft force (fig. 4). 
If the parameter $\delta_{0}$ is smaller than 1 , the influence of humidity is transmitted to the draft soil tillage force, which varies concave to the soil moisture, having a maximum point in the working range, [39]. The result is transferred also to the variation of the draft force to the working speed, [39]. Similar variations of the tensile strength (both horizontal and vertical), to soil density and moisture, have been reported in [18]. We remind that the density of the moist soil and its moisture are not independent parameters.

Generally, in theoretical and experimental works, we are accustomed to variations of the draft force in report to the working speed, which have the convex form (that is, the second derivative concerning the slightly negative speed), [15-16], [12], [20], [23], [24], and [32]. Some variations from this rule (some small portions on which the curve is concave) appear, for example in [19], and some experimental, laboratory data even show curves that appear to be slightly concave, at higher soil moisture (20\%), [31]. Moreover, in [32] (p. 74), after [33], it can be observed that the convex form is highlighted by inertial forces, and the concave component manifests itself due to static or other nature components. This behaviour is very interesting and can be a subject of research with many useful results. Results of the change in soil density at humidification similar to those given graphically in [32], page 110, can be obtained using the model proposed in this paper, using instead of a parabolic function, an exponential function of Gaussian type, for (13) :

$$
\delta\left(c_{w}\right)=1+B \cdot\left(e^{-\left(\frac{u_{0}-c_{w}}{c}\right)^{2}}-e^{-\left(\frac{u_{0}}{c}\right)^{2}}\right)
$$

When following the approximation of an experimental curve, it is recommended to calculate the parameters of the functions (13) and (23), using the least squares method.

For the variation of soil cohesion, [15] suggests by experimental results a law similar to density, and after cohesion through simple relationships, the dependence of soil adhesion on the metal body of the car can be calculated concerning the water content (moisture). We leave it to those interested to make this extension for the formula (model) (14) of the draft force. Also for a comfortable extension, it is possible to determine a dependence of the soil density on the working depth, which is easy to suspect due to the variation of the penetration resistance with the depth, noticed in numerous experimental works, for example [21] or [22].

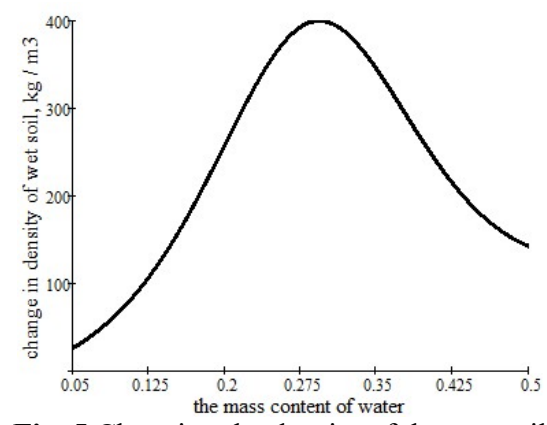

Fig. 5 Changing the density of the wet soil according to the water mass content.

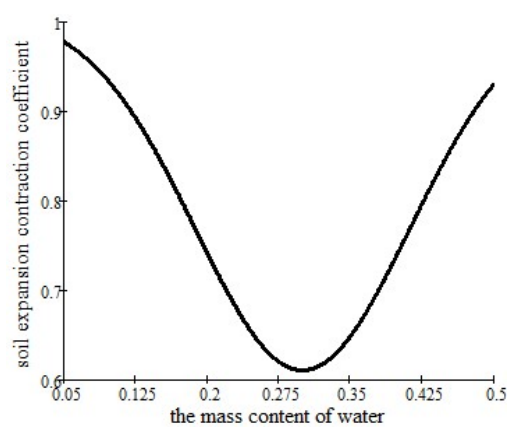

Fig. 6 Changing the density of the wet soil according to the water mass content.

$$
\rho_{\text {dry }}=750 \mathrm{~kg} / \mathrm{m}^{3}, \rho_{w}=1000 \mathrm{~kg} / \mathrm{m}^{3}, u_{0}=0.30, B=-0.4, c=0.158 \text {. }
$$

For the mathematical model of the draft force given in [29] and named in [30], "ASABE Universal Draft Equation", the situation is a little more complex since all the coefficients listed (four in numbers) are, hypothetically, dependent on humidity, texture, composition and soil structure. Further details about this case are given in [39]. 


\section{Conclusions}

This article describes a natural way of introducing soil moisture into formulas (mathematical models) of the draft tillage force. To this end, for better modelling of the phenomena of swelling or shrinkage of the volume of moistened soils, a mathematical model of the change of the density of the humidified soil in relation to the density of the same soil in the dry state was introduced. The proposed model has a number of important consequences in soil behaviour and implicitly in the behaviour of draft tillage force models. Using the model of the variation of soil density with its humidity, we succeeded in satisfying mathematical modelling of some experimental facts, especially the variation of the draft tillage force with the humidity. By this, it was shown that there is the possibility to approach the problem of optimum humidity even only from the narrow point of view of minimizing the draft tillage force (objective function).

It has been shown that the introduction of humidity into the alternative models (formulas) of the draft force can be done naturally, that is, through the known variation of some physical parameters of the soil with the moisture: soil density, cohesion, adhesion. In formulas in which not all these parameters appear explicitly, the model parameters (specific strengths, friction coefficients) can be expressed as a function of density, cohesion and adhesion and, consequently, the dependence of soil moisture appears.

In the same way that soil moisture was introduced in the tensile strength models, the texture, composition and structure of the soil can be introduced.

The phenomenon of the interaction between the soil and the working organs of the tillage machines is influenced by several tens of parameters. If each of them were introduced in the manner in which, in this article, soil moisture was introduced, very long calculation formulas would be obtained. The large length of the formulas favours the occurrence of writing errors (text and software) and increases the computation time. Therefore, it is recommended to keep a series of short, easy-to-write and calculating relationships, accompanied by an explanatory logic scheme, to use these increasingly refined models of the phenomenon as efficiently as possible.

In other words, such a multitude of relationships that can even reach the order of tens (also considering alternative formulas) loses the chances of constituting a physical law, at most it can "break" into several laws, supplemented by relations connection.

This work was supported by a grant of the Romanian Research and Innovation Ministry (RRIM), through Programme 1 - Development of the national research-development system, subprogram 1.2 Institutional performance - Projects for financing excellence in RDI, contract no. 16PFE, and was done by "NUCLEU" Programme, developed with the support of the RRIM, project PN 19100102.

\section{References}

1. P. Cardei, Tests for physical laws of the draft force generated in the tillage operations, preprint, DOI:10.13140/RG.2.2.16582.01607,(2019)

2. V. Popescu, Perioada optimă pentru lucrările solului, Lumea Satului, (2015)

3. V. Popescu, Lucrările solului ca la carte, Lumea Satului, (2014)

4. https://en.wikipedia.org/wiki/Water_content

5. https://graduo.ro/referate/ecologie/determinare-umiditate-in-sol-156286

6. T.W. Lambe,R.V. Whitman, Soil Mechanics, John Wiley \& Sons, Inc., p. 553, (1969)

7. C. M. P. Vaz, J.M. Manieri, I. Clerici De Maria, M.Th.Van Genuchten, Scaling the Dependency of Soil Penetration Resistance on Water Content and Bulk Density of Different Soils, Soil Science Society of America Journal, (2013) 
8. S. Manuwa, O., C. Ademosun, Draught and Soil Disturbance of Model Tillage Tines Under Varying Soil Parameters, Agricultural Engineering International: the CIGR Ejournal. Manuscript PM 06 016. Vol. IX. March, (2007)

9. S. Stadnic, Pedologie Curs de prelegeri, Universitatea de stat din Bălţi, (2010)

10. T. Demeter, Pedologie generala, Universitatea din Bucuresti, (2009)

11. A. Moeenifar, S.R. Mousavi-Seyedi, D. Kalantari, Influence of tillage depth, penetration angle and forward speed on the soil/thin-blade interaction force, Agric Eng Int: CIGR Journal, vol. 16, no.1, p. 69-74, (2014)

12. M.N. Letosnev, Masini Agricole, Editura Agro-Silvica de Stat, Bucuresti (1959)

13. P. Cardei, M. Matache M., C. Nutescu, Optimum working conditions for variable width ploughs, Preprint RG, (2017)

14. Cardei P., Draft force on soil tillage, model tests and relative ordering, DOI: 10.13140/RG.2.2.11951.89769, (2019)

15. G. Gebresenbet, Analysis of Forces Acting on Moulboard Ploghs and Seed Drill Coulters in Relation to Speed, Depth and Soil Conditions, Static and Dynamic Studies, Swedish University of Agricultural Sciences, Department of Agricultural Engineering, Uppsala, SLU Info/Repro, (1991)

16. P. Okoko, E.A. Ajav, W.A. Olosunde, Draft and power requirement for some tillage implements operating in clay loam soil, Agricultural Engineering International: CIGR Journal, 20(1): 95-102, (2018)

17. Lungu S., Consideratii privind cresterea durabilitatii organelor active de la masinile agricole pentru prelucrat solul si semanat, Teza de doctorat, Universitatea Tehnica Gheorghe Asachi din Iasi, (2014)

18. E.L. Bravo, H.M. Suarez, O.G. Cueto, C.I. Coronel, H. Ramon, Effect of Moisture and Soil Compaction on Tillage Operations, Revista Ciencias Técnicas Agropecuarias, Vol. 25, No. 1, pp. 32-37, (2016)

19. S. Ranjbarian, M. Askari, J. Jannatkhan, Performance of tractor and tillage implements inclay soil, Journal of the Saudi Society of Agricultural Science 16, 154-162, (2017)

20. G.T. Owen, Subsoiling forces and tool speed in compact soils, Can. Agric. Eng., 31, 15-20, (1988)

21. M.A. Ghazavi, Evaluation of a New Tillage Tool; Considering Soil Physical Property, Energy Requirement and Potato Yield, Pakistan Journal of Biological Sciences, Volume 10 (22): 4050-4056, (2007)

22. H.Th. Tahir, N.H. Jeejo, H. Tariq, T.H. Karim, A Comparative Study of Conventional and Modified Tine Types of Subsoiler and Their Effect on Some Performance Characteristics, Journal of Agricultural Machinery Science, 14 (1), 47-55, 2018

23. L. Naderloo, R. Alimadani, A. Akram, P. Javadikia, H. Z. Khanghah, Tillage depth and forward speed effects on draft of three primary tillage implements in clay loam soil, Journal of Food, Agriculture \& Environment Vol.7 (3\&4) : 382-385. (2009)

24. A.A.N. Ormenisan, Theoretical and experimental research concerning the influence of automatic control systems of the tractor linkage mechanisms on the dynamics and energetics of ploughing units, Thesis, University Transilvania, Brasov, (2014)

25. P. Cardei, A. Alexiou, M. Badescu, V. Vladut, N. Constantin, E. Marin, Nonlinear Friction and Resistance, Generating Sources of Optimal Points in the Energy Field of Agricultural Aggregates Working Process, Proceedings of the International Conference on Energy, Environment, Ecosystems and Development - Recent advances in energy, environment, ecosystems and development, (2013) 
26. A. Alexiou, P. Cardei, M. Badescu, V. Vladut, K.C. Selvi, I. Kiss, N. Constantin, E. Marin, New Viewpoints in Optimizing the Energetics of Working Processes of the Agricultural Aggregates, Annals of Faculty Engineering Hunedoara - International Journal of Engineering, Tome XI, fasc. 4, 2013

27. P. Cardei, A. Meca, G. Konstandinov, Working regimes of the agricultural machines designed to soil tillage: From optimization to fundamentals (1), INMATEHAgricultural Engineering, vol. 37, no. 2, 13-20, (2012)

28. P. Cardei, G. Konstandinov, Working regimes of the agricultural machines designed to soil tillage: From optimization to fundamentals (2), INMATEH-Agricultural Engineering, vol. 37, no. 2, 21-28, (2012)

29. American Society of Agricultural Engineers [ASAE]. 2003a. D497.4 Agricultural machinery management data. p. 373-380. In: ASAE. ASAE standards (2003)

30. V.K. Tewari, Tractor, implement and soil force consideration for tillage implement design, Lecture - $\quad$ 03, Farm Machinery, https://nptel.ac.in/content/storage2/nptel_data3/html/mhrd/ict/text/126105009/lec3.pdf

31. S.R.A. Zadeh, Modelling of energy requirements by a narrow tillage tool, Thesis, (2006)

32. E. McKyes, Soil Cutting and Tillage, Elsevier, (1985)

33. R.D. Wismer, H.J. Luth, Performance of plane soil cutting blades in a clay, Transactions A.S.A.E., Vol. 15, No. 2: pp. 211-216, (1972)

34. M. Mokhtari, M. Dehghani, Swell-Shrink Behavior of Expansive Soils, Damage and Control, Electronic Journal of Geotechnical Engineering, vol. 17, (2012)

35. Dexter A., R., Bird N., R., A., Methods for predicting the optimum and the range of soil water contents for tillage based on the water retention curve, Soil Tillage Research, 57(4), 203-212, (2001)

36. https://en.wikipedia.org/wiki/Optimum_water_content_for_tillage

37. P.B. Obour, J.L. Jensen, M. Lamande, C.W. Watts, L.J. Munkholm, Soil organic matter widens the range of water contents for tillage, Soil \& Tillage Research, 182:57$65,(2018)$

38. W. Hoogmoed, Tillage for soil and water conservation in the semi-arid tropics, Doctoral Thesis, Wageningen University, (1999)

39. P. Cardei, Soil moisture influence in the soil tillage operations, preprint, DOI: 10.13140/RG.2.2.28028.69768, (2019) 